\title{
Role of Assessing Cervical Length by Transvaginal Ultrasound before Induction of Labour
}

\author{
Sherine Marian ${ }^{1}$, Chidananda Murthy M$^{2}$, Rohit Kumar Sharma ${ }^{1}$, Prajwith Rai ${ }^{1}$, Francis N. P. Monteiro ${ }^{3}$ \\ ${ }^{1}$ Postgraduate CUM Tutor, Department of Radio-Diagnosis, A.J. Institute of Medical Sciences and Research Centre, NH 17, Kuntikana, Mangalore -575004, \\ ${ }^{2}$ Associate Professor, Department of Radio-Diagnosis, A.J. Institute of Medical Sciences And Research Centre, Nh 17, Kuntikana, Mangalore -575004, ${ }^{3}$ Professor, \\ Department Of Forensic Medicine \& Toxicology, A.J.Institute Of Medical Sciences And Research Centre, Nh 17, Kuntikana, Mangalore -575004.
}

\section{Abstract}

Background: Aims: The study aimed to evaluate the effectiveness of cervical length, measured by transvaginal ultrasound (TVS), to predict successful induction of labor at term and association of cervical length measurements with induction of labor. Subjects and Methods: A cross sectional study design was used to collect data was collected from 50 women between 36-40 weeks of gestation who presented at the study institute. Cervical length was measured using transvaginal ultrasound and the association of cervical length with induction of labour was examined. A p value <0.05 was considered as statistically significant. Results: Twenty one $(51.21 \%, 95 \%$ CI: 36.49, 65.74) of 41 pregnant women had successful induction of labour. The mean cervical length of the 41 study participants was $20.19 \pm 5.87$ (range 10 to 32 ) $\mathrm{mm}$. Twenty five women had a cervical length $<$ than 20 . Cervical length was associated (X2 test $\mathrm{p}=0.007$ ) with successful induction of labour. Mean cervical length was significantly different (student $\mathrm{t}$ test $\mathrm{p}=0.0003$ ) between women with successful induction of labour (17.14 $\pm 3.94 \mathrm{~mm})$ and women with failed induction of labour $(23.4 \pm 5.92 \mathrm{~mm})$.Cervical length showed slightly good sensitivity $(80.95 \%)$. It showed a positive predictive value of $68 \%$, negative predictive value of $75 \%$ and specificity of $60 \%$. Conclusion: Transvaginal ultrasound measures of cervical length before inducing a patient can help to identify women at risk for failed induction and reduce rate of unnecessary caesarean section and complications of prolonged and failed labour after induction.

Keywords: Antenatal ultrasound; Cervical length; Induction of labour; Pregnancy outcome after induction; Transvaginal ultrasound.

Corresponding Author: Dr. Chidananda Murthy. M, Associate Professor, Department of Radio-Diagnosis, A.J. Institute of Medical Sciences And Research Centre, Nh 17, Kuntikana, Mangalore -575004.

Received: March 2019

Accepted: March 2019

\section{Introduction}

Obstetricians induce labour as a lifesaving technique for mother and foetus, when physiological method of labour turns abnormal. A thorough knowledge of the basic mechanism of cervical shortening and ripening helps to choose additional management like induction of labour using oxytocin or prostaglandin. The decision whether to use prostaglandins or oxytocin to induce labour after ultrasonographic assessment of the uterine cervix has to be complemented with vaginal examination and usage of the Bishop score. ${ }^{[1-3]}$ A cervical score exceeding 8 is predictive of vaginal delivery, regardless of whether labour was induced or spontaneous. ${ }^{[4]}$

A vaginal digital examination is necessary as consistency of the cervix is the most significant feature to be evaluated, along with dilatation of the internal os. The evaluation of the cervix can help to assess the risk of failure of labour induction. In the cervix, elastic fibers are organized parallel to and between collagen fibers and assemble in a band 20$30 \mu \mathrm{m}$ thick. ${ }^{[5]}$ The elastin component can distend to twice its length during mechanical stress to allow the cervix to dilate for parturition. ${ }^{[6]}$ In 1981, Zemyln for the first time described, measurement of the cervix in pregnancy and since then, clinical significance of short cervix has been used in various other studies. ${ }^{[7]}$

A transvaginal ultrasound can be used to assess the cervix during pregnancy. Ultrasound is a high frequency mechanical vibration produced by a transducer that converts electrical signal into ultrasound energy and convert back reflected ultrasound energy into the electrical signal. ${ }^{[8]}$ In this study, we aimed to determine the effectiveness of cervical length, measured by transvaginal ultrasound (TVS), to predict successful induction of labor at term and association of cervical length measurements with induction of labor at a single tertiary care center in south India.

\section{Subjects and Methods}

The study was conducted at the Department of Radio diagnosis at AJIMS, Mangalore from October 2016 to October 2018. A cross sectional study design was used for the study and the study protocol was approved by the institutional ethics committee.

Pregnant women presenting between 36 to 40 gestation weeks, with a live singleton fetus and normal 
uncomplicated pregnancy were enrolled for the study. Informed consent was obtained from all participants prior to enrolment in the study. The study excluded pregnant women with uterine contractions, evidence of preterm rupture of membranes, cervical dilatation, a history of preterm birth, or previous cervical surgery. A convenience sample size of 50 was chosen for the study and study subjects were enrolled consecutively once they met the inclusion criteria and informed consent was obtained.

After enrolment, transvaginal ultrasonic cervical length measurement was performed. Ultrasonic cervical elastography study was performed using PHILLIPS IU22 ultrasound Machine with a TVS probe. All measurements were done by a single operator and a single machine.

Data were entered into a MS Excel spreadsheet and exported into SPSS v16.0 for statistical analysis. The mean and standard deviation of continuous variables and frequency distribution and proportions of categorical variables were determined. The mean of the cervical length measure was used to categorize subjects and to test associations with success of induction. A chi-square test was used for the statistical analysis and we considered a $\mathrm{p}$ value $<0.05$ as statistically significant.

\section{Results}

Seventy pregnant women underwent induction of labour at the study institute during the study period. Fifty of these 70 women met the criteria for inclusion in the study and were enrolled. We could not assess the outcomes of induction of labour in 9 of these 50 women as they underwent a caesarean section due to premature rupture of membrane with meconium stained liquor and foetal distress.

Table 1: Association of cervical length and outcomes of induction in the study population

cervical length * outcome Crosstabulation

\begin{tabular}{|c|c|c|c|c|c|}
\hline & & & \multicolumn{2}{|c|}{ outcome } & \multirow{2}{*}{ Total } \\
\hline & & & 0 & 1 & \\
\hline \multirow{4}{*}{$\begin{array}{l}\text { cervical } \\
\text { length }\end{array}$} & \multirow[t]{2}{*}{$<20$} & Count & 17 & 8 & 25 \\
\hline & & $\begin{array}{c}\% \text { within cervical } \\
\text { length }\end{array}$ & $68.0 \%$ & $32.0 \%$ & $100.0 \%$ \\
\hline & \multirow[t]{2}{*}{$>20$} & Count & 4 & 12 & 16 \\
\hline & & $\begin{array}{c}\% \text { within cervical } \\
\text { length }\end{array}$ & $25.0 \%$ & $75.0 \%$ & $100.0 \%$ \\
\hline \multirow{2}{*}{\multicolumn{2}{|c|}{ Total }} & Count & 21 & 20 & 41 \\
\hline & & $\begin{array}{c}\% \text { within cervical } \\
\text { length }\end{array}$ & $51.2 \%$ & $48.8 \%$ & $100.0 \%$ \\
\hline
\end{tabular}

\begin{tabular}{|c|c|c|c|}
\hline \multicolumn{2}{|l|}{ Chi-Square Tests } \\
\hline & Value & df & Asymp. Sig. (2-sided) \\
\hline $\begin{array}{c}\text { Pearson Chi- } \\
\text { Square }\end{array}$ & 7.220 & 1 & .007 \\
\hline N of Valid Cases & 41 & & \\
\hline
\end{tabular}

Twenty-one $(51.21 \%, 95 \%$ CI: $36.49,65.74)$ of these 41 pregnant women had successful induction of labour and 20 of them had failed induction of labour. The mean cervical length of the 41 study participants was $20.19 \pm 5.87$ (range 10 to 32 ) $\mathrm{mm}$. Twenty-five women had a cervical length $<$ than 20. Cervical length was associated (X2 test $p=0.007)$ with successful induction of labour (see Table-1) with a diagnostic odds ratio of 6.06 (95\% CI: 1.52, 28.12). Mean cervical length was significantly different (student $t$ test $\mathrm{p}=0.0003$ ) between women with successful induction of labour (17.14 $\pm 3.94 \mathrm{~mm})$ and women with failed induction of labour $(23.4 \pm 5.92 \mathrm{~mm})$. Considering outcome of induction of labour as gold standard we calculated the sensitivity, specificity, positive predictive value and negative predictive value. Ultrasound evaluation of the cervix showed slightly good sensitivity $(80.95 \%)$, a positive predictive value of $68 \%$, negative predictive value of $75 \%$ and specificity of $60 \%$.

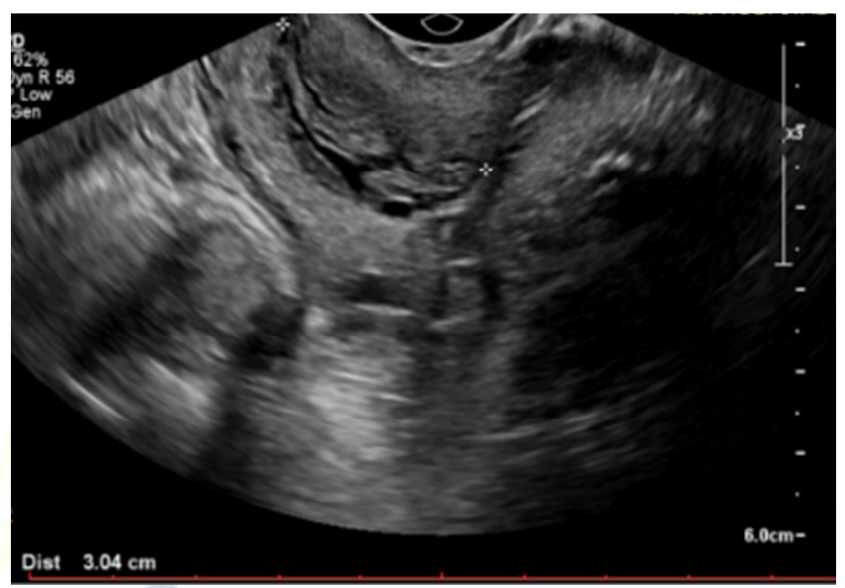

Figure 1: Grey Scale Image Showing Measurement Of Length Of Cervix

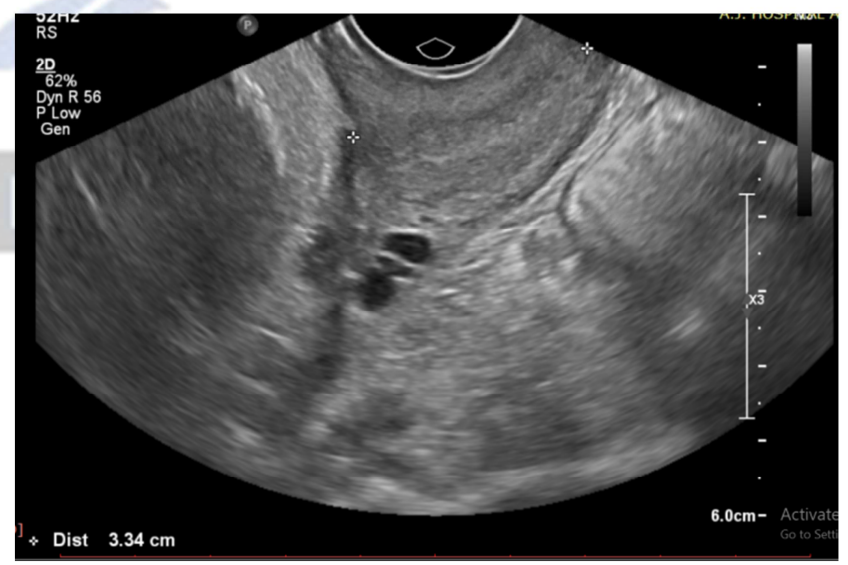

Figure 2: Grey Scale Image Showing Measurement Of Length Of Cervix

\section{Discussion}

Induction of labour is an increasingly prevalent obstetric intervention with approximately 1 in 4 pregnant women receiving an induction of labour. ${ }^{[9]}$ The approach to obstetric management in the latent phase varies between providers and institutions. ${ }^{[10]}$ One approach to defining a failed induction was to consider the latent phase beginning when oxytocin was initiated and membrane rupture had occurred and ending when there was either $4 \mathrm{~cm}$ dilation and 90 effacement or $5 \mathrm{~cm}$ dilation regardless of effacement. ${ }^{[11]}$ A recent study reported that the majority of women undergoing induction of labour will enter the active phase 
within 15 hours and that maternal adverse events become more frequent with greater time in the latent phase. ${ }^{[12]}$ In this study, we considered women with a Bishop score of less than 5 for induction as these are the ideal patients for induction of labour. A previous study has reported very unfavourable Bishop score on admission as predictive of caesarean section. ${ }^{[13]}$ A previous study from India reported that a Bishops score $>4$ was the best cutoff value to predict active labour within 6 hours and the best cutoff value for cervical length was $25 \mathrm{~mm}$ or less. ${ }^{[14]}$ Another study from India reported that cervical length measurement by transvaginal ultrasonography is an independent predictor of successful labour induction. ${ }^{[15]}$ Another study reported that transvaginal ultrasonography was less painful than digital vaginal exams and that both Bishops score $(>=5)$ and cervical length $(>20 \mathrm{~mm})$ measures were independent predictors of the need for caesarean delivery. ${ }^{[16]}$ A metaanalysis reported that cervical elastography and cervical length (diagnostic odds ratio 3.35, 95\% CI: 1.95, 5.77) measurements are similarly reliable in the prediction of successful labour. ${ }^{[17]}$ In our study, the diagnostic odds ratio was 6.06 .

The single operator measurement on a single machine is strength of the study that limits measurement bias. The single tertiary care center nature of the study maybe a limitation as the study population may not be representative of the general population.

\section{Conclusion}

Ultrasonic transvaginal cervical length measurement is a simple, safe, repeatable and cost-effective modality of imaging. Various studies including our study has proved that the cervical length has good correlation in predicting the outcome of labour.

Ultrasound has been poorly utilized in predicting the outcome of labour. However, our study has showed that ultrasound evaluation is useful in evaluating cervix and predicting outcome of induction of labour. Therefore, ultrasound evaluation of cervix is recommended before inducing a patient to reduce to rate of unnecessary caesarean section and complications of prolonged and failed labour after induction.
1. Celik E, To M, Gajewska K, Smith GC, Nicolaides KH; Fetal Medicine Foundation Second Timester Screening Group. Cervical length and obstetric history predict spontaneous preterm birth: development and validation of a model to provide individualized risk assessment. Ultrasound ObstetGynecol 2008; 31: 549-554. 2.

2. Chao AS, Chao A, Hsieh PC. Ultrasound assessment of cervical length in pregnancy. Taiwan J ObstetGynecol 2008; 47: 291-295. 3.

3. Bishop EH. Pelvic scoring for elective induction. Obstet Gynecol. 1964;24:266-268.

4. Yoshida K, TaharaR,Nakayama T, Yanahara T . Effect of dehydroepiandrosterone sulphate ,estrogens and prostaglandins on collagen metabolism in human cervical tissue in relation to cervical ripening . J Int Med Res.1993;21:26-35.

5. Bruno carbonne, Cervical maturation and labourinduction ,Hypertens Res Pregnancy 2014;2:59-64

6. Rechberger T, Woessner JF Jr. Collagenase, its inhibitors, and decorin in the lower uterine segment in pregnant women. Am J Obstet Gynecol.1993;168:1598-1603.

7. Zemlyn S. The length of the uterine cervix and its significance. J Clin Ultrasound. 1981;9(6):267-269.

8. Park SE.,ShroutTR. Characteristics of relaxer based piezoelectric crystal for ultrasound transducer IEEE transactions ultrasonic ferroelectrics frequency control.1988;45:1071-1076.

9. Martin JA, Hamilton BE, Osterman MJ, Curtin SC, Mathews TJ. Births: final data for 2013. Natl Vital Stat Rep. 2015; 64: 1-65

10. Banos N, Migliorelli F, Posadas E, Ferreri J, Palacio M. Definition of failed induction of labour and its predictive factors: two unslved issues of an everyday clinical situation. Fetal Diagn Ther. 2015; 38(3):161-9

11. Rouse DJ, Owen J, Hauth JC. Criteria for failed labor induction: prospective evaluation of a standardized protocol. Obstet Gynecol. 2000;96: 671-7

12. Grobman WA, Bailit J, Lal Y, Reddy UM, Wapner RJ, Varner MW, et al. Defininf failed induction of labour. Am J Obstet Gynecol 2018;218(1):122e1-122e8

13. Oros D, Garcia-Simon R, Clemente J, Fabre E, Romero MA Montanes A. Predictors of perinatal outcomes and economic costs for late-term induction of labour. Taiwan J Obstet Gynecol 2017;56(3): 286-90

14. Khandelwal R, Patel P, Pitre D, Sheth T, Maitra N. Comparison of cervical length measured by transvaginal ultrasonography and Bishop Score in prediciting response to labour induction. J Obstet Gynecol India. 2018; 68(1): 51-57

15. Maitra N, Sharma D, Agarwal S. Transvaginal measurement of cervical length in the prediction of successful induction of labour. J Obstet Gynaecol 2009; 29(5): 388-91

16. Tan PC, Vallikannu N, Suguna S, Quek KF, Hassan J. Transvaginal sonographic measurement of cervical length vs Bishop Score in labor induction at term: Tolerability and prediction of caesarean delivery. Ultrasound Obstet Gynecol 2007; 29(5): 568-73

17. Londero AP, Schmitz R, Bertozzi S, Driul L, Fruscalzo A. Diagnostic accuracy of cervical elastography in predicting labour induction success: a systematic review and meta-analysis. J Perinat Med 2016;44(2): 167-78

\section{References}

Copyright: () the author(s), publisher. Asian Journal of Medical Radiological Research is an Official Publication of "Society for Health Care \& Research Development". It is an open-access article distributed under the terms of the Creative Commons Attribution Non-Commercial License, which permits unrestricted non-commercial use, distribution, and reproduction in any medium, provided the original work is properly cited.

How to cite this article: Marian S, Murthy MC, Sharma RK, Rai P, Monteiro FNP. Role of Assessing Cervical Length by Transvaginal Ultrasound before Induction of Labour. Asian J. Med. Radiol. Res. 2019;7(1):29-31.

DOI: dx.doi.org/10.21276/ajmrr.2019.7.1.7

Source of Support: Nil, Conflict of Interest: None declared. 